\title{
Evaluation of improved bi-manual endoscopic resection using a customizable 3D-printed manipulator system designed for use with standard endoscopes: a feasibility study using a porcine ex-vivo model
}

\section{다)(i) $(-)$}

\author{
Authors \\ Institutions \\ 1 Department of Internal Medicine I, University Hospital \\ of Ulm, Ulm, Germany \\ 2 Department of Mechanical Engineering, Institute of \\ Micro Technology and Medical Device Technology \\ (MIMED), Technical University of Munich, Munich \\ Germany \\ 3 MITI Research Group, Department of General and \\ Visceral Surgery, Technical University of Munich, \\ Munich, Germany \\ 4 Medical Clinic and Policlinic II, University Hospital \\ Würzburg, Würzburg, Germany
}

Benjamin Walter ${ }^{1}$, Yannick S. Krieger ${ }^{2}$, Dirk Wilhelm³ ${ }^{3}$ Hubertus Feussner ${ }^{3}$, Tim C. Lueth², Alexander Meining ${ }^{4}$

submitted 26.11.2020

accepted after revision 3.2.2021

Bibliography

Endosc Int Open 2021; 09: E881-E887

DOI 10.1055/a-1395-7089

ISSN 2364-3722

(c) 2021. The Author(s).

This is an open access article published by Thieme under the terms of the Creative Commons Attribution-NonDerivative-NonCommercial License, permitting copying and reproduction so long as the original work is given appropriate credit. Contents may not be used for commercial purposes, or adapted, remixed, transformed or built upon. (https://creativecommons.org/licenses/by-nc-nd/4.0/)

Georg Thieme Verlag KG, Rüdigerstraße 14,

70469 Stuttgart, Germany

Corresponding author

Benjamin M. Walter, MD, Universitätsklinik Ulm, Klinik für Innere Medizin I, Albert-Einstein-Allee 23, 89081 Ulm,

Germany

Fax: +49-731-500-44819

Benjamin.walter@uniklinik-ulm.de
\# Supplementary material is available under https://doi.org/10.1055/a-1395-7089

\section{ABSTRACT}

Background and study aims A major drawback of endoscopic en-bloc resection technique is its inability to perform bimanual tasks. Although endoscopic platforms that enable bimanual tasks are commercially available, they are neither approved for various locations nor adaptable to specific patients and indications.

Methods Based on evolution of an adaptive 3D-printable platform concept, system variants with different characteristic properties were evaluated for ESD scenarios, ex-vivo in two locations in the stomach and colorectum.

Results In total 28 ESDs were performed (7 antrum, 7 corpus in inversion, 7 cecum, 7 rectum) in a porcine ex-vivo setup. ESD was feasible in 21 cases. Investigated manipulator variants are differently well suited for performing ESD within the varying interventions scenarios. Dual-arm manipulators allowed autonomous ESD, while single-arm flexible manipulators could be used more universally due to their compact design, especially for lesions difficult to access. Pediatric scopes were too frail to guide the overtubemanipulators in extremely angled positions. Working in the rectum was impaired using long-sized manipulator arms.

Conclusions The presented endoscopic platform based on 3D-printable and customizable manipulator structures might be a promising approach for future improvement of ESD procedure. With regard to localization, especially flexible manipulators attached to standard endoscopes appear to be most promising for further application of specific and individualised manipulator systems.

\section{Introduction}

Endoscopic submucosal dissection (ESD) can be considered for en-bloc resection of early cancers, non-lifting and recurrent neoplasms in the gastrointestinal tract [1]. Under expert hands, excellent outcomes and low complication can be achieved [2] However, the procedure is still a time consuming and challenging task as location of the lesion, size and fibrosis are named as a major impediments for successful ESD [3-4]. Transitional techniques exist to improve endoscopic traction include clip- 

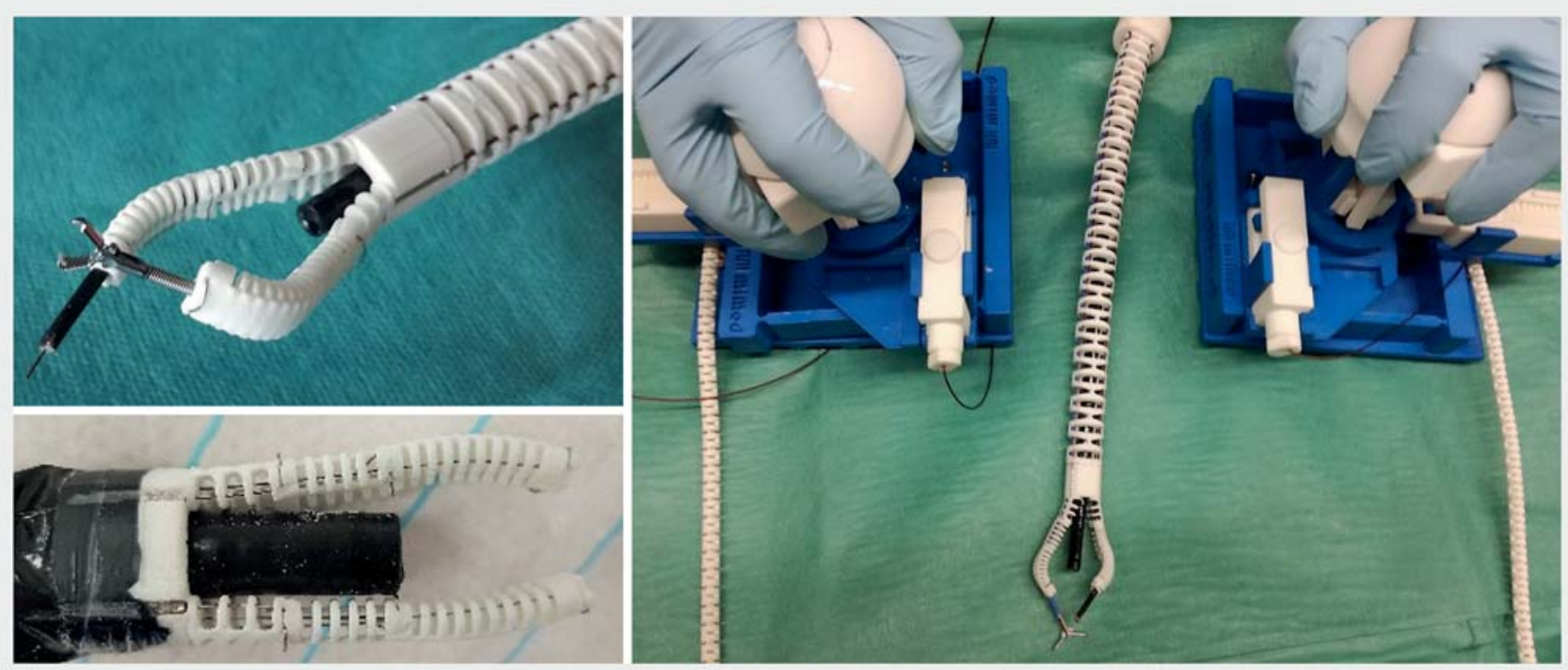

Fig. 1 Dual-arm manipulators.

with-line method, sinker-assisted method, or magnetic anchors [5-7].

A further major drawback of the current technique is its inability to perform bimanual tasks. Endoscopes used for ESD allow only a yaw and pitch movement of the endoscope tip as well as a translatory movement of the endoscopic instruments within the working channel and parallel to the endoscope shaft [8-10]. Meanwhile, endoscopic bimanual platform concepts are commercially available but at present limited to certain indications [11].

We describe the further evolution and preclinical evaluation of different system versions of a 3D-printed manipulator system for standard endoscopes for performing endoscopic resection [12].

\section{Methods}

The Single-Port-Overtube Manipulator-System (SPOT) is a customizable manipulator system designed for standard endoscopes for use in endoscopic procedures. The automated design process for the customizable manipulator structures is based on a adaptable monolithic flexure hinge design (Supplementary Fig. 1) [13]. The manipulator structures are manufactured using selective laser sintering of biocompatible polyamide (PA2200, EOS, Krailling, Germany) in combination with surface smoothing (PostPro3D, AMT, Sheffield, UK), which allows to fabricate flexure hinge structures that are able to withstand several thousand of actuation cycles without damage. This makes them usable for the application as disposable manipulators. The surface smoothed parts showed no cytotoxic effects after testing according to ISO 10993-5. In order to optimally adapt the system to the requirements of the application different dual- and single-arm versions for the manipulator structures and control concepts and were manufactured and evaluated.
The dual-arm endoscopic manipulator consists of three flexure hinge chain sections which are used to reproduce the degrees of freedom of the human arm (shoulder joint with two DoF; ellbow joint with one DoF) ( $\boldsymbol{\sim}$ Fig. 1 ). In addition the forward and backward movement of the instrument in the working channel, as well opening and closing of the instrument has also been integrated. To actuate the instruments autonomously during ESD a pushbutton was inserted into the spherical control element ( $\vee$ Video 1 and $\vee$ Video 2 ). The outer diameters of the systems are $20 \mathrm{~mm} \times 15 \mathrm{~mm}$ using standard and $16 \mathrm{~mm} \times 11 \mathrm{~mm}$ using pediatric gastroscope.

The single-arm endoscopic manipulator offers the possibility to use an additional standard instrument with the described five DoF (three DoF manipulator arm and two DoF instrument movement and actuation). Either an endoscopic forceps or the cautery tool can be guided in the manipulator arm. A forceps, guided in the arm, offers the possibility to manipulate the tissue, while cutting movement is carried out via the movement of the endoscope tip ( $\bullet$ Fig. 2 ).

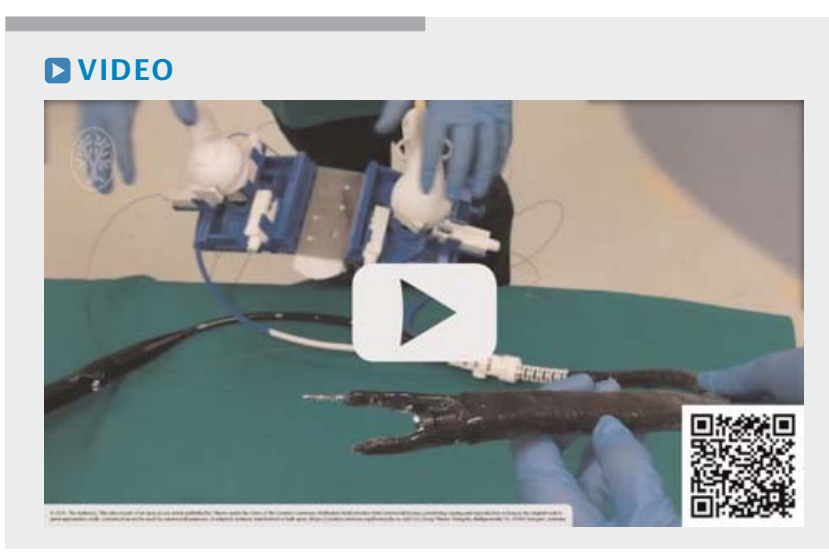

- Video 1 Video dual-arm control unit. 


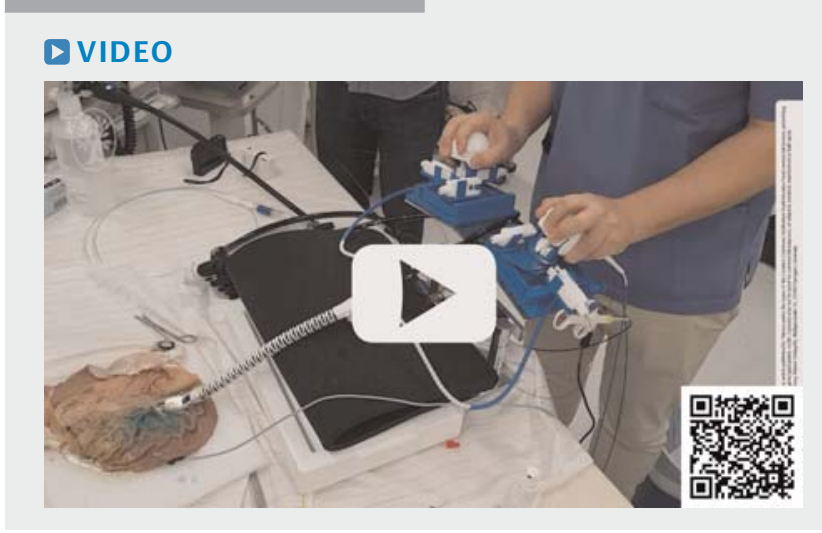

- Video 2 Open stomach model training for demonstration of the dual-arm manipulator-enhanced ESD procedure. The outer diameter of the overtube system is $20 \mathrm{~mm} \times 15 \mathrm{~mm}$.

The outer diameters of the system can be reduced to $15.5 \mathrm{~mm} \times 15 \mathrm{~mm}$ using standard and $11.5 \mathrm{~mm} \times 11 \mathrm{~mm}$ using a pediatric gastroscope.

The behind-the-tip-mounted manipulator with handheld control device (HDC) is a system variant that has a manipulator arm with three DoF. The manipulator arm is attached to the

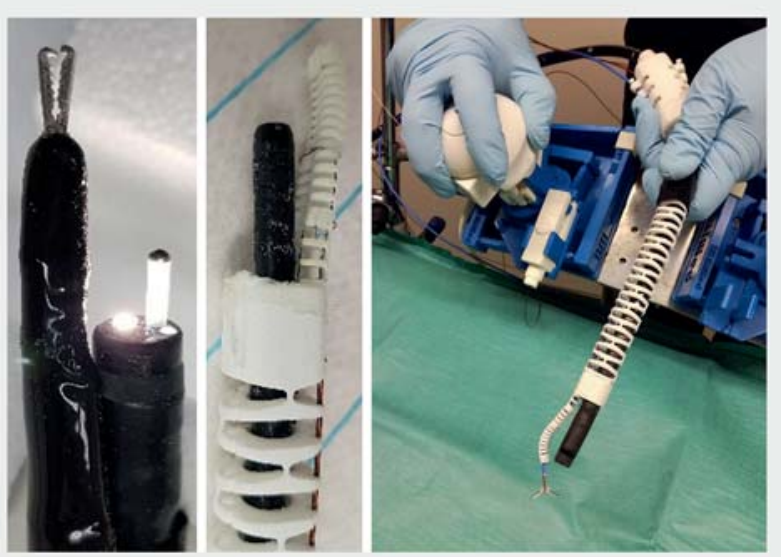

- Fig. 2 Single-arm manipulators.

proximal end of the movable tip of the endoscope. The deployment of the arm with the first DoF prevents the movement of the endoscope from being restricted so that the endoscope can move under the arm without collision.

Tip-mounted one arm manipulator with handheld control device (HDC): This variant is characterized by a short manipula-
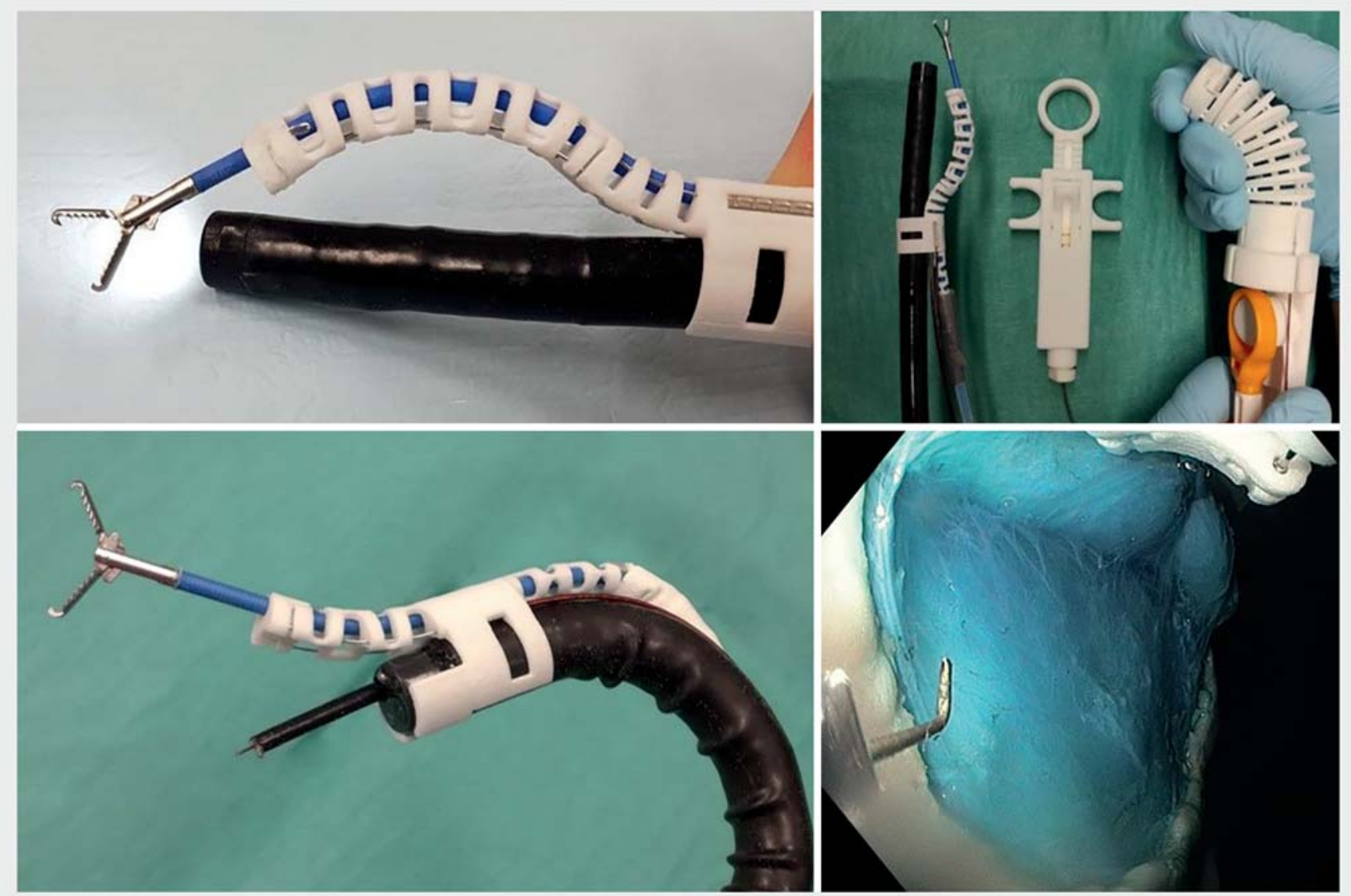

- Fig. 3 Behind-the-tip mounted and tip-mounted single-arm manipulators. 
tor arm which is fixed to the distal end of the endoscope. The flexure hinges are arranged parallel and alternating to realize the two DoF in one short flexure hinge chain section. Both systems are designed for use with a standard gastroscope (> Fig.3).

To actuate the manipulator two control units (CU) were evaluated. First, a mountable CU. The purely mechanical control concept has already been described in principle [12].The design was extended by the push-button for the instrument actuation ( $\triangleright$ Video 1 ). Second a handheld control device (HDC). The cutting movement is carried out as conventionally via the movement of the endoscope tip. For an intuitive control concept, the manipulator arm movement is directly transferred to a flexible input element with identical DoF. Furthermore, the backand-forth movement of the instrument in the working channel is generated by a pushing movement at the handheld input device and the opening and closing of the instrument can be controlled via the thumb ( $\vee$ Video 3 ).

The focus of the present study was to evaluate the feasibility of ESD with the new systems. ESD was performed in a porcine ex-vivo model. Standard (Olympus GIF HQ160) and pediatric gastroscope (Olympus GIF-XP160N) were used for endoscopic resection. ESD was either performed by a single operator (endoscopist highly skilled in ESD) or with further assistance

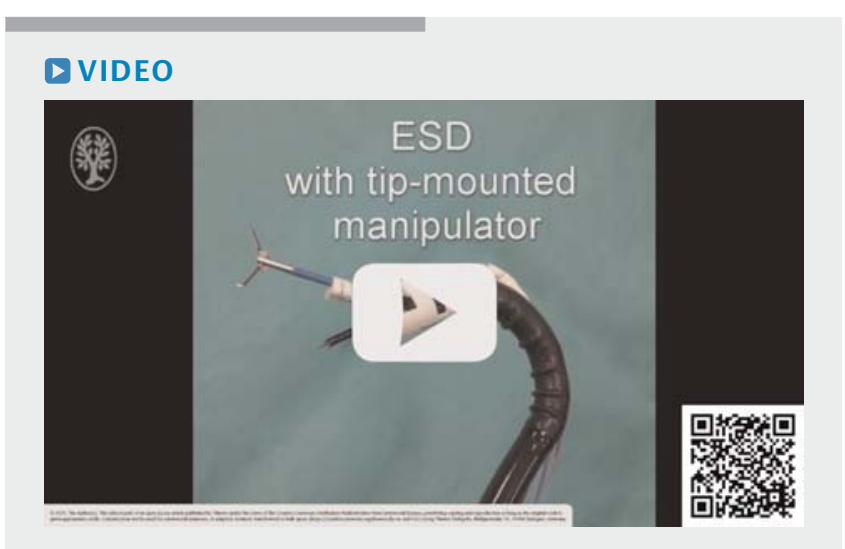

- Video 3 Video ESD with a tip-mounted single-arm manipulator with handheld control device.

by another experienced endoscopist (single-arm HDC and standard ESD).

ESD was performed as follows. The colon or stomach was turned inside out prior the resection. Before intervention, standardized 30-mm lesions were marked in antrum, corpus, rectum or cecum with a marking probe (Ovesco, Germany) (Supplementary Fig.3). The colon or stomach was turned

- Table 1 Results of standard and enhanced ESD in an ex-vivo model in the upper gastrointestinal tract.

\begin{tabular}{|c|c|c|c|c|c|c|c|}
\hline Location & Technique & Endoscope & Manipulators & $\begin{array}{l}\text { En-bloc resec- } \\
\text { tion }(y / n)\end{array}$ & $\begin{array}{l}\text { Resection } \\
\text { time (min) }\end{array}$ & $\begin{array}{l}\text { Resected area } \\
\text { time }\left(\mathrm{cm}^{2} / \mathrm{min}\right)\end{array}$ & $\begin{array}{l}\text { Adverse events/ } \\
\text { comments }\end{array}$ \\
\hline \multirow[t]{7}{*}{ Antrum } & Standard & Standard & $\mathrm{n} / \mathrm{a}$ & $\mathrm{Y}$ & 22.25 & 0.32 & None \\
\hline & Overtube & Standard & 1 & Y & 13.26 & 0.53 & None \\
\hline & Overtube & Pediatric & 2 & $\mathrm{Y}$ & 13.43 & 0.53 & None \\
\hline & Overtube & Standard & 2 & $\mathrm{Y}$ & 27.32 & 0.26 & None \\
\hline & Overtube & Pediatric & 1 & Y & 23.17 & 0.31 & None \\
\hline & Tip mounted & Standard & 1 & $\mathrm{Y}$ & 9.83 & 0.72 & None \\
\hline & $\begin{array}{l}\text { Behind tip } \\
\text { mounted }\end{array}$ & Standard & 1 & $\mathrm{Y}$ & 18.58 & 0.38 & None \\
\hline \multirow[t]{7}{*}{ Corpus } & Standard & Standard & $\mathrm{n} / \mathrm{a}$ & $Y$ & 14.72 & 0.48 & None \\
\hline & Overtube & Standard & 1 & $\mathrm{~N}$ & $\mathrm{n} / \mathrm{a}$ & $\mathrm{n} / \mathrm{a}$ & $\begin{array}{l}\text { Restricted arm move- } \\
\text { ment }\end{array}$ \\
\hline & Overtube & Pediatric & 2 & $\mathrm{~N}$ & $\mathrm{n} / \mathrm{a}$ & $\mathrm{n} / \mathrm{a}$ & Endoscope too fragile \\
\hline & Overtube & Standard & 2 & $\mathrm{~N}$ & $\mathrm{n} / \mathrm{a}$ & $\mathrm{n} / \mathrm{a}$ & $\begin{array}{l}\text { Restricted arm move- } \\
\text { ment }\end{array}$ \\
\hline & Overtube & Pediatric & 1 & $\mathrm{~N}$ & $\mathrm{n} / \mathrm{a}$ & $\mathrm{n} / \mathrm{a}$ & Endoscope too frail \\
\hline & Tip mounted & Standard & 1 & $\mathrm{Y}$ & 7.25 & 0.98 & None \\
\hline & $\begin{array}{l}\text { Behind tip } \\
\text { mounted }\end{array}$ & Standard & 1 & Y & 19.17 & 0.37 & None \\
\hline \multicolumn{8}{|c|}{$\begin{array}{l}\text { t; Technique: Standard = standard endoscopic submucosal resection; Endoscope: Standard: Olympus GIF HQ } 160 \text {; Pediatric: Olympus GIF XP160N. The outer diame- } \\
\text { ters of the single-arm overtube systems were } 15.5 \mathrm{~mm} \times 15 \mathrm{~mm} \text { for standard and } 11.5 \mathrm{~mm} \times 11 \mathrm{~mm} \text { for pediatric gastroscope; for the dual-arm systems, } 20 \mathrm{~mm} \times 15 \\
\mathrm{~mm} \text { using standard and } 16 \mathrm{~mm} \times 11 \mathrm{~mm} \text { using pediatric gastroscope; the outer contour measured } 14.5 \mathrm{~mm} \times 10.5 \mathrm{~mm} \text { for tip-mounted and behind-the-tip-mounted } \\
\text { single-arm manipulator. Resection Time: Time needed for submucosal injection, incision and complete resection of premarked specimen. } \\
\text { ESD, endoscopic submucosal dissection; } \mathrm{Y} \text {, yes; } \mathrm{N}, \mathrm{no} ; \mathrm{n} / \mathrm{a} \text {, not applicable. }\end{array}$} \\
\hline
\end{tabular}


- Table 2 Results for standard and enhanced ESD in ex-vivo model in the lower gastrointestinal tract.

\begin{tabular}{|c|c|c|c|c|c|c|c|}
\hline Location & Technique & Endoscope & $\begin{array}{l}\text { Manipu- } \\
\text { lators }\end{array}$ & $\begin{array}{l}\text { En-bloc resection } \\
(y / n)\end{array}$ & $\begin{array}{l}\text { Resection } \\
\text { Time (min) }\end{array}$ & $\begin{array}{l}\text { Resected area/ } \\
\text { time }\left(\mathrm{cm}^{2} / \mathrm{min}\right)\end{array}$ & $\begin{array}{l}\text { Adverse events/ } \\
\text { comments }\end{array}$ \\
\hline \multirow[t]{7}{*}{ Cecum } & Standard & Standard & $\mathrm{n} / \mathrm{a}$ & Y & 22.5 & 0.31 & None \\
\hline & Overtube & Standard & 1 & Y & 35.0 & 0.20 & None \\
\hline & Overtube & Pediatric & 2 & $\mathrm{~N}$ & $\mathrm{n} / \mathrm{a}$ & $\mathrm{n} / \mathrm{a}$ & Endoscope too frail \\
\hline & Overtube & Standard & 2 & Y & 9.12 & 0.78 & None \\
\hline & Overtube & Pediatric & 1 & $\mathrm{~N}$ & $\mathrm{n} / \mathrm{a}$ & $\mathrm{n} / \mathrm{a}$ & Endoscope too fragile \\
\hline & Tip mounted & Standard & 1 & Y & 6.33 & 1.12 & None \\
\hline & $\begin{array}{l}\text { Behind tip } \\
\text { mounted }\end{array}$ & Standard & 1 & $\mathrm{Y}$ & 12.85 & 0.55 & None \\
\hline \multirow[t]{7}{*}{ Rectum } & Standard & Standard & $\mathrm{n} / \mathrm{a}$ & Y & 16.38 & 0.43 & None \\
\hline & Overtube & Standard & 1 & Y & 18.87 & 0.37 & None \\
\hline & Overtube & Pediatric & 2 & Y & 31.67 & 0.22 & None \\
\hline & Overtube & Standard & 2 & Y & 21.93 & 0.32 & None \\
\hline & Overtube & Pediatric & 1 & Y & 12.42 & 0.57 & None \\
\hline & Tip mounted & Standard & 1 & Y & 22.02 & 0.32 & None \\
\hline & $\begin{array}{l}\text { Behind tip } \\
\text { mounted }\end{array}$ & Standard & 1 & $\mathrm{~N}$ & $\mathrm{n} / \mathrm{a}$ & $\mathrm{n} / \mathrm{a}$ & $\begin{array}{l}\text { Restricted arm move- } \\
\text { ment }\end{array}$ \\
\hline
\end{tabular}

Technique: Standard = standard endoscopic submucosal resection. Endoscope: Standard: Olympus GIF HQ 160; Pediatric: Olympus GIF XP160N. The outer diameters of the single-arm overtube systems were $15.5 \mathrm{~mm} \times 15 \mathrm{~mm}$ for standard and $11.5 \mathrm{~mm} \times 11 \mathrm{~mm}$ for pediatric gastroscope; for the dual-arm systems, $20 \mathrm{~mm} \times 15 \mathrm{~mm}$ using standard and $16 \mathrm{~mm} \times 11 \mathrm{~mm}$ using pediatric gastroscope. The outer contour measured $14.5 \mathrm{~mm} \times 10.5 \mathrm{~mm}$ for tip-mounted and behind-the-tip-mounted single-arm manipulator. Resection time: Time needed for submucosal injection, incision and complete resection of premarked specimen. ESD, endoscopic submucosal dissection; Y, yes; N, no; n/a, not applicable.

again and sutured. The respective endoscope and manipulator were introduced ( $\vee$ Video 3 , Supplementary Fig. 2 ). For bimanual operations, the platform of the endoscope was fixed in an endoscope docking station (ScopeDoc, Cook, United States) around the endoscopist's abdomen [12]. Thereby both hands were free to control the left and right manipulator arm via each of the two spherical control elements, respectively. For handheld device approach the endoscopist was assisted by another experienced endoscopist. Submucosal injection of $0.003 \%$ indigo Carmine saline solution was applied via regular working channel. For dual-arm manipulator system Hook-Knife (Olympus, KD-625QR) was inserted through right manipulator working channel. A grasping forceps was inserted through the left manipulator working channel respectively. Change of sides of the tools was permitted within procedure. For pediatric endoscopes a combined snare-inflator tool was used due to diameter of the regular working channel (Olympus, Japan). The lesions were resected located in the upper and lower gastrointestinal tract. Resection specimen were retrieved and analyzed for en-bloc resection state. The following parameters were assessed for all ESD procedures; anatomic location, performed ESDtechnique, resection time, en-bloc resection state, adverse events and comments. The resection speed of the respective procedure was assessed by calculating the ratio of the resected area over time $\left(\mathrm{cm}^{2} / \mathrm{min}\right)$.

\section{Results}

In total 28 ESDs were performed (7 each in the antrum, corpus in inversion, cecum, rectum). ESD was feasible in 21 cases. In seven cases, the ESD was terminated because of too frail Bowden wires or too long manipulator arms. The manipulator enhanced procedures were performed with single- and dualarm manipulators on slim or standard scopes respectively ( $\triangleright$ Table 1 and $\triangleright$ Table 2). All feasible ESDs were performed enbloc with all markings visible after retrieval. Frail pediatric scope manipulators to guide the passive overtube manipulators into positions of larger deflection, therefore they could not be used adequately for resection working in inversion and for lesions located in the cecum. Dual-arm manipulators offered option for autonomously performed ESD. Single-arm manipulator equipped standard endoscopes offered best results in optimal traction-countertraction during ESD. This resulted in a significant improvement of resection speed in comparison with standard ESD technique ( $\mathbf{F i g . 4}$ ). No perforation was observed during manipulator enhanced ESD.

\section{Discussion}

ESD is an effective but challenging and time-consuming technique for en-bloc resection of malignant lesions. Several innovative approaches have been evaluated to facilitate ESD proce- 


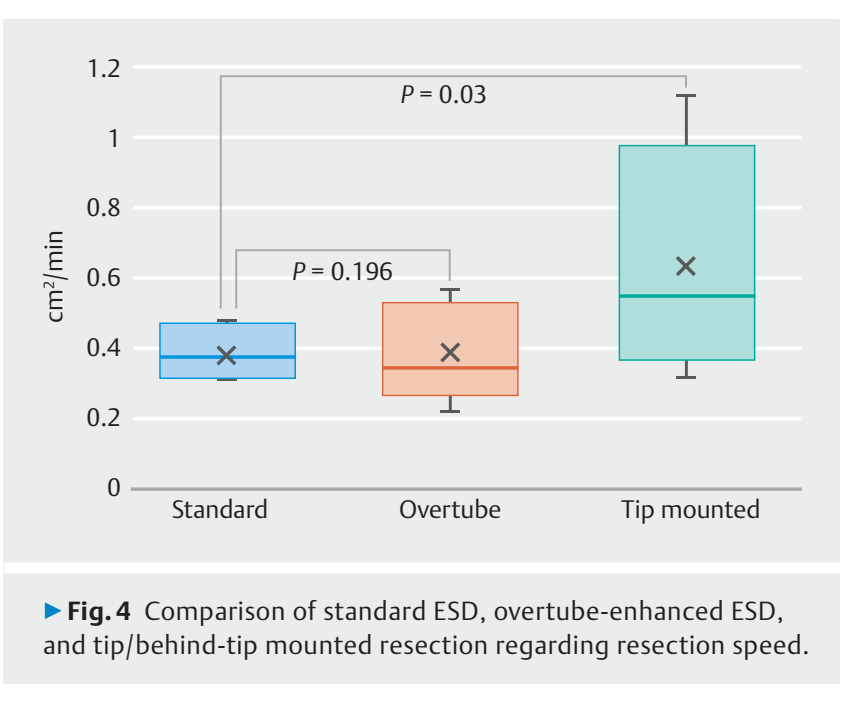

dure. However, the current technique is still limited by impossibility of bimanual handling of tools. The Endo-Lifter offers only traction, standard dual-channel endoscopes enable grasp-andcut technique, but are limited by lack of triangulation. Endoscopic innovations like DiLumenC2 or Flex Robotic System and are limited to special indications. Robotic platform approaches as EndoMaster, i²Snake or Anubis enable bimanual manipulation within endoscopic procedures $[14,15]$. A major disadvantage of these might be the potential high costs and the demanding and costly reprocessing by disinfection or sterilisation. In contrast, the SPOT-system is designed as a disposable for use with standard instruments. The customizable SPOT-system enables independent movement of one or two additional arms for endoscopic resection in both upper and lower GI tract as demonstrated in this study.

We acknowledge several limitations of this study. First, an ex-vivo model was used due to the focus on feasibility in study design. This might limit the transferability of the results towards in-vivo ESD. So further interventional studies are mandatory. Second, the diameter especially of the dual-armed SPOTsystem is still object of limitation towards clinical use. The diameter of the entire system depends strongly on the internally guided gastroscope, so single-arm solutions might be preferable. Since slim SPOT-systems for pediatric endoscopes could not prove feasibility due to limited movability of the passive overtube shaft structure, the integration of actuated shaft structures could be a further development.

\section{Conclusions}

Based on our preliminary data we conclude that ESD is feasible using an individualized manipulator system designed for standard endoscopes. Resection in angulated position still remains more challenging and susceptible to faults for both standard procedure and manipulator enhanced ESD. The applicable forces of the manipulator arms are sufficient to lift and stretch tissue using standard endoscopic instruments. Dual-arm manipulators offer options for the endoscopist to work autonomously without further assistance. However, a learning curve for the endocopist is expected and they are limited by their larger diameter for use especially in the rectum and partially in the antrum. A single-arm manipulator system attached onto a standard gastroscope with handheld control device appears to offer the optimum utilization of traction and countertraction during endoscopic resection even in difficult locations. In summary, the presented platform concept provides a promising opportunity to enable short-term design and further evaluation of application-specific and indivudalized manipulator systems for endoscopic resection in the future.

\section{Acknowledgements}

This work was supported and funded by the Deutsche Forschungsgemeinschaft (DFG), Grant FOR1321.

\section{Competing interests}

The authors declare that they have no conflict of interest.

\section{References}

[1] Pimentel-Nunes P, Dinis-Ribeiro M, Ponchon T et al. Endoscopic submucosal dissection: European Society of Gastrointestinal Endoscopy (ESGE) Guideline. Endoscopy 2015; 47: 829-854

[2] Kim ER, Chang DK. Management of complications of colorectal submucosal dissection. Clin Endosc 2019; 52: 114-119

[3] De Ceglie A, Hassan C, Mangiavillano B et al. Endoscopic mucosal resection and endoscopic submucosal dissection for colorectal lesions: A systematic review. Crit Rev Oncol Hematol 2016; 104: 138-155

[4] Oyama T, Yahagi N, Ponchon T et al. How to establish endoscopic submucosal dissection in Western countries. World J Gastroenterol 2015; $21: 11209-11220$

[5] Oyama T. Counter traction makes endoscopic submucosal dissection easier. Clin Endosc 2012; 45: 375-378

[6] Tsuji K, Yoshida N, Nakanishi H et al. Recent traction methods for endoscopic submucosal dissection. World J Gastroenterol 2016; 22: 5917-5926

[7] Nishizawa T, Yahagi N. Endoscopic mucosal resection and endoscopic submucosal dissection: technique and new directions. Curr Opin Gastroenterol 2017; 33: 315-319

[8] Diana M, Chung H, Liu K-H et al. Endoluminal surgical triangulation: overcoming challenges of colonic endoscopic submucosal dissections using a novel flexible endoscopic surgical platform: feasibility study in a porcine model. Surg Endosc 2013; 27: 4130-4135

[9] Walter B, Schmidbaur S, Krieger Y et al. Improved endoscopic resection of large flat lesions and early cancers using an external additional working channel (AWC): a case series. Endosc Int open 2019; 7: E298E301

[10] de Melo SW, Cleveland P, Raimondo M et al. Endoscopic mucosal resection with the grasp-and-snare technique through a double-channel endoscope in humans. Gastrointest Endosc 2011; 73: 349-352

[11] Kantsevoy SV, Bitner M, Piskun G. New endoscopic platform for endoluminal en bloc tissue resection in the gastrointestinal tract (with videos). Surg Endosc 2016; 30: 3145-3151

[12] Zizer E, Roppenecker D, Helmes F et al. A new 3D-printed overtube system for endoscopic submucosal dissection: first results of a randomized study in a porcine model. Endoscopy 2016; $48: 765$ 
[13] Krieger YS, Roppenecker DB, Kuru I et al. Multi-Arm Snake-Like Robot. in IEEE International Conference on Robotics and Automation (ICRA 2017). Singapore, May 20-June 03, 20172017; 2490-2495
[14] Takeshita N, Ho KY, Phee S] et al. Feasibility of performing esophageal endoscopic submucosal dissection using master and slave transluminal endoscopic robot. Endoscopy 2017; 49: E27-E28

[15] Peters BS, Armijo PR, Krause C et al. Review of emerging surgical robotic technology. Surg Endosc 2018; 32: 1636-1655 